\section{CEREBRAL VASCULAR DISEASE}

\section{Cerebral Infarction}

By Alan Barham Carter. Pp. xi +209 . (London and New York: Pergamon Press, 1964.) 63s. net.

$\mathrm{T}$

HE energy and skill devoted by generations of neurologists to diagnosis and to locating a pathological process in the nervous system have not often been extended to a study of prognosis. This is an understandable failing; it is only too easy to foretell the future course of most cerebral tumours, while in the early stages of the demyelinating diseases it may be virtually impossible. In spite of these difficulties, ignorance of the natural history of common nervous disorders is remarkable and standard texts give widely differing views on the prognosis of such everyday conditions as petit mal or cerebral haemorrhage, views which are often unsupported by adequate evidence. In Cerebral Infarction, Dr. Barham Carter, a general physician with an interest in cerebral vascular disease, has remedied some defects in the specialists' knowledge. By the simple methods of long-term, planned clinical observation he has collected information of a kind not available elsewhere, and the chapters on the course and outcome of the different types of cerebral infarction and on the effects of treatment are invaluable. Results are clearly stated and well set out, although some important facts, such as the interval between the onset of the stroke and the beginning of treatment, have been omitted.

The author is less at home in the scientific aspects of vascular disease. The opening chapter deals adequately with the anatomy of the cerebral vessels, apart from an expensive and inaccurate colour plate and some questionable facts about anastomoses between cerebral arteries. The section on physiology is short and there is little reference to the newer methods of measuring blood flow. In spite of poor photomicrographs the chapter on arterial pathology is clearly set out, although not all pathologists would agree with the account of the evolution of fatty streaks to atheromatous plaques. No mention is made of thrombotic thrombopenic purpura or of embolism with atheromatous debris.

The major syndromes of cerebral embolism and thrombosis are well described, but it is strange to find nothing about hypertensive encephalopathy or the diffuse type of cerebral arteriosclerosis resulting in Parkinsonism and pseudo-bulbar palsy. There is little new information on surgical treatment, but previous work is well reviewed.

In the final chapters on rehabilitation of hemiplegic patients there is much that is practical and helpful, but the photographs would be better as line drawings and the comments on physiological principles in physiotherapy could well have been omitted. In general, the illustrations are excellent, especially the radiographs and line drawings, and this must account for the high cost.

This book should inspire those in the medical profession who feel that the absence of laboratory facilities, research assistants and the trappings of the teaching hospital has deprived them of the chance to do worth-while clinical research.

Ross Russelx

\section{PROBLEMS OF DRUGS AND SOCIETY}

\section{Drugs in Our Society}

Edited by Paul Talalay, assisted by Jane H. Murnaghan. (Based on a Conference sponsored by the Johns Hopkins University.) Pp. viii + 311. (Baltimore, Md.: The Johns Hopkins Press; London: Oxford University Press, 1964.) 48s. net.

IN autumn 1963, at the Johns Hopkins University, a distinguished professional group assembled to discuss problems associated with the discovery, development, manufacture, testing, pricing and use of drugs. They included doctors, scientists, jurists, economists, educators, drug manufacturers and public officials. Drugs in Our Society is the first published record of the Johns Hopkins meetings. Here are twenty-one papers from the conference, together with a summary of the discussions which they provoked.

The first papers deal with the progress and present limitations of drug therapy, and with the evaluation of drug effectiveness and safety. The next group of essays discusses the responsibilities of the pharmaceutical industry and the functions of Government in the field of drugs. Problems of drug economics, including incentives, drug costs, and advertising to consumer and physician, are considered in four related papers. A final section of the book explores the sociological, legal and ethical problems of drugs in our society. Paul Talalay, the editor of the book, is the John Jacob Abel professor and director of the Department of Pharmacology and Experimental Therapeutics, the Johns Hopkins University School of Medicine.

Although there are papers by Sir John Gaddum, director of the Agricultural Research Council Institute of Animal Physiology, Babraham, and R. M. Titmuss, of the London School of Economics, the book is most useful and interesting because of the light which it sheds on drugs in the American Continent. There are remarkable differences in national expenditures. Britain, Holland and Denmark appear to be the three low-cost countries, while expenditures on drugs in France, Western Germany, the United States and Italy are 50 per cent to 200 per cent higher. Differences of this order are puzzling and cannot be explained without much more research. They are even larger and more difficult to explain when wo include a number of low-income countries in Latin America and Africa for which some statistics are available.

Two hundred years ago Voltaire defined medical treatment as the art of pouring drugs of which one knew nothing into a patient of whom one knew less. It was not until medical therapeutics began to deserve the name of a science in the 1940's that this cynical generalization lost some of its validity. Even so, most physicians trained in Western countries and practising to-day in all countries of the world completed their training before the flowering of this scientific revolution in therapeutics. It has even been said that any doctor who has been out of medical school for five years and has not learnt any more is practising out-dated medicine.

W. L. SUMNER

\section{HISTORY, MEDICINE AND PHILOSOPHY}

Doctors Past and Present

By Lord Brain. Pp. viii +270 . (London: Pitman Medical Publishing Co., Ltd., 1964.) 40s. net.

THE essays and addresses collected in this volume were written between 1953 and 1963 , and it says much for their author's judgment and selection that they could just as well have all been written and published in 1965 . The topics and problems discussed are of abiding interest and importance, ranging from the seventeenth century to the present day.

Among the historical essays, which occupy about onehalf the volume, we welcome several familiar figures whom we have come to recognize as Lord Brain's particular intimates, Dr. Johnson in particular, with occasional references to Swift, De La Mare, and Dickens. A former president of the Royal College of Physicians must also have long communed with the shade of its 'favourite son', William Harvey, and it is fitting that he should have chosen for his own contribution to the long series of Harveian Orations (now beginning their fourth century) 